\title{
Effects of Emulsified Sausage Supplemented with Ginseng Saponin on Lipid Metabolism in Rat
}

\author{
Kwan-Seob Shim* \\ Institute of Agricultural Science and Technology, Chonbuk National University, Jeonju 561-756, Korea
}

\begin{abstract}
The current study was designed to assess the effects of emulsified sausage supplemented with ginseng saponin on lipid metabolism by applying a rat model. Four groups of 8 rats ( $5 \mathrm{wk}$ old) were each allocated one of 4 treatments: basal feed (C), and basal feed with $20 \%$ sausage powder containing $0 \%$ (S0), $2 \%$ (S2) and 4\% (S4) ginseng saponin. The experiment was conducted for $4 \mathrm{wk}$. The results did not differ among the treatments with different amounts of sausage (ST), but daily feed intake $(p<0.01)$ and feed conversion $(p<0.001)$ were significantly increased in STs compared to C. Both total serum cholesterol and triglyceride concentrations were significantly $(p<0.001)$ reduced, by 45 and $46 \%$, and 48 and $46 \%$, in S2 and $\mathrm{S} 4$, respectively, compared to S0. In the liver, the total cholesterol level was dramatically $(p<0.05)$ decreased according to increasing sausage powder levels. In particular, S4 showed approximately $14 \%$ reduction compared to S0 $(p<0.05)$. Liver triglyceride content also showed a similar tendency, where S2 and S4 resulted in $7 \%$ and $31 \%$ reduction. With regard to fatty acid composition in the liver tissues, palmitic acid (16:0), oleic acid (18:1), eicosanoic acid (20:1), and eicosatrienoic acid (20:3) did not differ among the STs, whereas both linoleic acid (18:2) $(p<0.01)$ and linolenic acid $(18: 3)(p<0.001)$ showed significant increases in S2 compared to S0. The current data demonstrated that emulsified sausages supplemented with ginseng saponin effectively reduce total cholesterol and triglyceride concentrations in the serum and liver, and increase unsaturated and essential fatty acid in the liver. These data collectively imply that the sausage improved the overall lipid profile in a rat model, and can be further generalized to the result that emulsified sausage can improve lipid metabolism depending on the products' formula.
\end{abstract}

Key words: emulsified sausage, ginseng, saponin, lipid metabolism, fatty acid composition

\section{Introduction}

The current dietary trend worldwide is toward increasing fat intake, and this is especially true in more developed countries. In parallel with this trend, the prevalence of cardiovascular system diseases such as arteriosclerosis and coronary arterial diseases, as well as chronic degenerative diseases such as diabetes mellitus and obesity, are also rising (Lee, 1996). In particular, it has been demonstrated that, among the different types of hyperlipidemia, hypercholesterolemia is a primary causative factor of coronary arterial diseases (Cho et al., 2000) and hypercholesterolemia can be caused or exacerbated by excessive fat intake and increased intake of animal-based foods (Kurata et al., 1990). Ingestions of large quantities of saturated fatty acid are a risk factor for diseases associated

*Corresponding author: Kwan Seob Shim, Institute of Agricultural Science and Technology, Chonbuk National University, Jeonju 561-756, Korea. Tel: 82-63-270-2608, Fax: 82-63-2702614, E-mail: sks909@hanmail.net with lipid metabolism, and excessive oxygen in vivo triggers peroxidation reactions in the form of active oxygen or free radicals; the resultant peroxides cause damage to cells, thereby not only hindering cellular functions but also potentially triggering cancers, aging, and a variety of degenerative diseases (Hamsten, 1988).

In general, in case of emulsified sausage, fat content can be added up to $35 \%$ but many researchers recommend reducing intake of total fat, saturated fatty acid and cholesterol contents to minimize the damage of health (Choi and Chin, 2002; Pearson et al., 1987). For this reason, consumers want to take "healthier foods" which are functional food products. However, consumption of processed meat products in Korea is relatively small part of whole meat consumption, referring other countries. The prime reason for the phenomenon is likely related to the failure of responding consumer's demand who increasingly demand functional foods including meat and meat products. Thus, many laboratories and researchers are exploring various useful materials to use in the functional food industry.

With regard to ginseng (Panax ginseng C.A. Meyer), 
studies of saponin began in earnest after Brekhman and Dardymov (1969) identified saponin glycosides as the principal component responsible for the medicinal effects of saponin; as a result of this research, the structure and biochemical and pharmacological effects of saponin have been assessed and elucidated in great detail. The Korea Ginseng and Tobacco Laboratory (1983) reported that, although ginseng is composed of a large number of compounds, including glycosides, fatty acids, peptides, and polyethylene compounds, its major active ingredient is saponin. Lee et al. (2002) analyzed the total saponin contents of Korean red ginseng and on the basis of their results, they reported a content of approximately $3.05-3.76 \%$ and a ginsenoside content of approximately $1.47 \%$, including $\mathrm{Rb}_{1}(0.47$ $0.49 \%), \mathrm{Rb}_{2}(0.16-0.18 \%), \mathrm{Rc}(0.17-0.19 \%)$, Rd (0.06$0.07 \%), \operatorname{Re}(0.21-0.23 \%)$ and $\operatorname{Rg}_{1}(0.35-0.38 \%)$.

Saponin has been recognized broadly as an effective constituent compound of ginseng, and thus a variety of effects have been attributed to saponin, including: accelerating basal metabolism, promoting protein synthesis, adjusting hypertension, adjusting glycosuria, anti-cancer effects, strengthening the central nervous system, antioxidant effects and hematopoiesis and diverse efficiencies (Moon, 1985). It has also been fairly well established that ginseng saponin is involved in lipid metabolism in vivo, and it appears to exert some powerful lipid-reduction effects. For example, several reports have asserted that saponin is tightly associated with disease conditions originating in lipid or cholesterol metabolism disorders, including hypertension (Stavro et al., 2005), hyperlipidemia (Wen et al., 1996; Yang et al., 1999), hypercholesterolemia (Lin et al., 1993), and arteriosclerosis (Zhang et al., 2008). Many of the effects of ginseng saponin, such as the suppression of increases in blood cholesterol contents, promotion of cholesterol excretion, prevention of blood vessel lesions caused by hypercholesterolemia, and the amelioration of arteriosclerosis via induced reductions in low-density lipoprotein (LDL) cholesterol and increases in high-density lipoprotein (HDL) cholesterol levels have been continuously elucidated in animal experiments (Yamamoto et al., 1983). Therefore, the current study was designed to assess functionality of emulsified sausage supplemented with ginseng saponin on lipid metabolism by applying a rat model.

\section{Materials and Methods}

\section{Animal and experimental design}

Five-wk-old Sprague-Dawley male rats (Damul Sci- ence, Daejon) were obtained, and were fed on commercial pellet diets for one wk to allow them to acclimate to the environment. Animals were fed on ground pellet diets for one wk to allow them to re-adjust back to powdered feed. After the adaption period was completed, 8 of $160 \pm 10 \mathrm{~g}$ rats were randomly assigned and housed in individual cages with controlled room temperature $\left(22^{\circ} \mathrm{C}\right)$ and light cycles (lights on, 08:00 AM - 08:00 PM). The experimental diets shown in Table 1 were prepared by making sausages containing 0,2 , and $4 \%$ ginseng saponin, grinding them, and then drying the samples for $48 \mathrm{~h}$ at $105^{\circ} \mathrm{C}$; this procedure generates a powdered feed with a ginseng saponin content of $20 \%$. The animals were divided into 4 experimental groups and raised for $4 \mathrm{wk}$.

\section{Feed intake, body weight, weight gain and feed conversion}

During the raising period, feed intake was measured once per wk; differences between the total amounts supplied and the residual amount was calculated and expressed as the average daily consumption. Body weight was measured once per wk and weight gain was calculated as the difference between final body weight and beginning body weight. Feed conversion was calculated by dividing the average daily consumption by the daily weight gain.

\section{Blood and liver sampling}

After the 4-wk raising period was finished, the animals were fasted for $24 \mathrm{~h}$. Blood was collected from the carotid and then the liver was immediately removed. The livers were immediately stored into physiological saline for removing blood, then weighed after wiping with a Kimwipe. To obtain the serum, the collected blood was left for $30 \mathrm{~min}$ at room temperature and centrifuged for $20 \mathrm{~min}$ at $2500 \mathrm{rpm}$. The serum and liver samples were stored at $-20^{\circ} \mathrm{C}$ until further analysis.

\section{Analysis of triglyceride concentration}

Triglyceride concentrations in the serum and liver were analyzed via enzymatic colorimetric methods using Cleantech TG-S kits (Asan Pharm Co., Korea). The serum

Table 1. Experimental design

\begin{tabular}{ccl}
\hline \hline Treatment & No. of rat & \multicolumn{1}{c}{ Experimental diet } \\
\hline C & 8 & Basal diet \\
S0 & 8 & Basal diet $+20 \%$ sausage powder (20\% SP) \\
S2 & 8 & Basal diet $+20 \%$ SP contained $2 \%$ saponin \\
S4 & 8 & Basal diet $+20 \%$ SP contained 4\% saponin \\
\hline
\end{tabular}


$(0.02 \mathrm{~mL})$ was mixed slowly with $3 \mathrm{~mL}$ of the enzyme test solution (lipoprotein lipase, glycerol kinase, peroxidase, L- $\alpha$-glycerophosphate oxidase, $N, N$-bis (2-hydroxy ethyl)-2-aminomethane, sulfonic acid buffer), maintained for $10 \mathrm{~min}$ at $37^{\circ} \mathrm{C}$, and measured at $550 \mathrm{~nm}$ within 60 min. Blanks made by mixing distilled water with the enzyme test solution prepared via the same method were used. Serum triglyceride concentrations were calculated based on the glycerin standard test solution and expressed in $\mathrm{mg} / \mathrm{dL}$. To measure triglyceride contents in the liver, lipids were separated via the method previously established by Folch et al. (1957). In brief, $1 \mathrm{~g}$ of liver tissue was mixed with $15 \mathrm{~mL}$ of Folch solution (chloroform : methanol $=2: 1)$, homogenized at room temperature $(30$ seconds $\times 2$ times, $14,000 \mathrm{rpm}$, Ultra Turrax, IKA labortechnik, Malaysia) and maintained overnight at $4^{\circ} \mathrm{C}$. The solution was filtered (Whatman No. 1) and Folch solution was added to a volume of $20 \mathrm{~mL}$. Then, $4 \mathrm{~mL}$ of distilled water was added to the filtered solution, mixed and maintained overnight at $4^{\circ} \mathrm{C}$. The upper solution was then removed and $1 \mathrm{~mL}$ of the upper phase (chloroform:methanol:D.W =3:48:47) was added and left for $30 \mathrm{~s}$ then removed. The volume of the above-mentioned sample was adjusted to the same $20 \mathrm{~mL}$ with Folch's solution and the chloroform was evaporated in a $35^{\circ} \mathrm{C}$ dry oven to extract the lipids. The extracted lipids were then divided into subsamples of $500 \mu \mathrm{L}$ each after weighing, and stored at $-20^{\circ} \mathrm{C}$. Triglyceride concentrations in the liver were measured by adding $3 \mathrm{~mL}$ of the enzyme test solution to $0.2 \mathrm{~mL}$ of the lipid extracted, followed by measurement in precisely the same manner as serum triglyceride concentrations were measured. The data were expressed in units of $\mathrm{mg}$ per $\mathrm{g}$ tissue.

\section{Analysis of total cholesterol concentration}

The total cholesterol contents in the serum and in the liver were measured by enzymatic colorimetric methods using Cleantech TG-S kits (Asan Pharm Co., Korea). The serum $(0.02 \mathrm{~mL})$ was mixed with $3 \mathrm{~mL}$ of the enzyme test solution (cholesterol esterase, cholesterol oxidase, potassium phosphate dibasic and phenol) and allowed to react for 5 minutes at $37^{\circ} \mathrm{C}$, and the optical density of the solution was measured at $500 \mathrm{~nm}$. A blank made by mixing distilled water with the enzyme test solution via the same method was used. The total cholesterol content was calculated based on a cholesterol standard, and expressed in $\mathrm{mg} / \mathrm{dL}$. The total cholesterol content in the liver was measured by adding $3 \mathrm{~mL}$ of the enzyme test solution to $0.2 \mathrm{~mL}$ of the extracted lipids and measured via the same method as total serum cholesterol content and expressed in $\mathrm{mg}$ per $\mathrm{g}$ tissue.

\section{Analysis of HDL-cholesterol and LDL-cholesterol concentrations}

Serum HDL-cholesterol was measured using Cleantech TG-S kits (Asan Chemical Co., Korea) via enzymatic colorimetric methods. The separated serum $(0.02 \mathrm{~mL})$ was mixed thoroughly with $0.2 \mathrm{~mL}$ of the separation test solution (sodium phosphotungstic acid, magnesium chloride), allowed to react for $10 \mathrm{~min}$ at room temperature and centrifuged for $10 \mathrm{~min}$ at $3,000 \mathrm{rpm}$. Then, $0.1 \mathrm{~mL}$ of the supernatant was separated and mixed with $3 \mathrm{~mL}$ of the enzyme test solution (cholesterol esterase, cholesterol oxidase, sodium hydroxide, potassium phosphate dibasic, and phenol) and allowed to react for $5 \mathrm{~min}$ at $37^{\circ} \mathrm{C}$, after which the solution's optical density was measured at 500 $\mathrm{nm}$. A blank made by mixing $0.1 \mathrm{~mL}$ of distilled water with the enzyme test solution via the same method was used. Serum HDL-cholesterol contents were calculated based on a cholesterol standard and expressed in $\mathrm{mg} / \mathrm{dL}$. Serum LDL-cholesterol was calculated using the following formula and expressed in $\mathrm{mg} / \mathrm{dL}$ (Friedewald et al., 1972). LDL-cholesterol $=\{$ total cholesterol $-[$ HDL-cholesterol $+($ neutral fat $/ 5)]\}$

\section{Analysis of fatty acid composition}

To analyze the fatty acid composition in the rats' livers, $0.5 \mathrm{~g}$ portions of the samples were taken and methylated in accordance with the method developed by Park and Goins (1999). Each of the samples was mixed with $2 \mathrm{~mL}$ of methanol : benzene $(4: 1, \mathrm{v} / \mathrm{v})$ and $200 \mu \mathrm{L}$ of acetyl chloride, then heated for one hour in a $100^{\circ} \mathrm{C}$ heating block. The sample was then maintained at room temperature for a sufficient period of time, mixed with $2 \mathrm{~mL}$ of hexane and $5 \mathrm{~mL}$ of $6 \%$ potassium carbonate, and centrifuged for 15 minutes at 3,000 rpm. The supernatant (1 $\mu \mathrm{L}$ ) was injected into the GC-MSD (Agilent $6890 \mathrm{~N}$, USA). The analysis conditions were as follows. The temperature of the column was raised to $200^{\circ} \mathrm{C}$ at a speed of $25^{\circ} \mathrm{C} / \mathrm{min}$ from an initial temperature of $50^{\circ} \mathrm{C}$, and then raised to $230^{\circ} \mathrm{C}$ at a speed of $3^{\circ} \mathrm{C} / \mathrm{min}$ and maintained for $18 \mathrm{~min}$. The temperatures of the inlet and the detector (MSD) were controlled at 250 and $280^{\circ} \mathrm{C}$, respectively.

\section{Statistical analysis}

In order to assess the effects of saponin on serum lipid levels and the fatty acid composition of liver tissues, least square means were determined using the general linear 
model (SAS, 1997) and the significance of differences between treatments was calculated via pair tests at a level of $0.05 \%$.

\section{Results and Discussion}

\section{Growth performance}

During the raising period (4 wk), sausages containing differing levels of ginseng saponin were supplied to the experimental rats. Growth performance and liver weights were measured and the results are provided in Table 2. Although the final body weights did not differ among the treatment groups, weight gains were significantly $(p<0.05)$ lower in group S4 than in the control group, whereas there were no differences among the sausage addition groups. Feed intake $(p<0.01)$ and feed conversion $(p<$ 0.001 ) were significantly higher in the sausage addition groups as compared to the control group, respectively, whereas there were no differences among the sausage addition groups. There were no significant differences among the experimental groups in terms of liver weights and the liver-to-body weight ratios.

\section{Serum lipid concentration}

Blood lipid contents are used as a diagnostic index of cardiovascular system diseases such as arteriosclerosis, hypertension, heart diseases, and hyperlipidemia (Inkeles and Eisenberg, 1981). Many researchers are looking for physiologically active components in natural materials that might reduce blood cholesterol and triglyceride concentrations and increase HDL-cholesterol concentrations (Cha et al., 2000; Kim et al., 2001).

The effect of sausages containing added ginseng saponin on the serum total cholesterol, triglyceride, HDL-cholesterol and LDL-cholesterol concentrations of rats are presented in Table 3. Total cholesterol concentrations increased significantly $(p<0.001)$, by approximately $24 \%$, in the S0 group as compared to the control group, and significantly reduced $(p<0.001)$, by approximately 45 and $46 \%$ in the S2 and S4 groups, respectively, as compared to the S0 group. The serum triglyceride concentrations did not differ significantly between the control group and S0 group, although those in the S0 group were higher. Our results showed that the saponin added to the sausages caused significant $(p<0.001)$ reductions in serum triglyceride concentrations, by approximately 48 and $46 \%$ in the S2 and S4 groups, respectively, compared to the S0 group. These results were similar to the results of a study conducted by Joung and Cho (1985), who reported that when 25 and $50 \mathrm{mg}$ per $\mathrm{kg}$ of ginseng saponin were administered to rats for a period of $4 \mathrm{wk}$, the total cholesterol concentrations were reduced by $11 \%$ in the $50 \mathrm{mg} /$ $\mathrm{kg}$ treatment group as compared to the control group, and triglyceride concentrations were reduced in both the 25 and $50 \mathrm{mg} / \mathrm{kg}$ administration groups. Also, according to the results of a similar experiment, total cholesterol con-

Table 2. Least square means and pair differences for growth performance and liver weight as a function of basal feeding (C) and $20 \%$ of sausage supplementation containing $0 \%$ saponin (S0), $2 \%$ saponin (S2), or $4 \%$ saponin (S4)

\begin{tabular}{lcccccc}
\hline \hline \multicolumn{1}{c}{ Items } & $\mathrm{C}(\mathrm{n}=8)$ & $\mathrm{S} 0(\mathrm{n}=8)$ & $\mathrm{S} 2(\mathrm{n}=8)$ & $\mathrm{S} 4(\mathrm{n}=8)$ & SEM $^{\mathrm{l})}$ & F value \\
\hline Initial body weight $(\mathrm{g})$ & $200.8^{\mathrm{a}}$ & $213.0^{\mathrm{a}}$ & $209.0^{\mathrm{a}}$ & $211.1^{\mathrm{a}}$ & 5.57 & 0.93 \\
Final body weight $(\mathrm{g})$ & $358.0^{\mathrm{a}}$ & $354.9^{\mathrm{a}}$ & $345.1^{\mathrm{a}}$ & $343.4^{\mathrm{a}}$ & 8.62 & 0.69 \\
Body weight gain (g) & $157.3^{\mathrm{a}}$ & $141.9^{\mathrm{ab}}$ & $136.1^{\mathrm{ab}}$ & $132.3^{\mathrm{b}}$ & 7.47 & $2.16^{*}$ \\
Daily feed intake (g) & $23.6^{\mathrm{a}}$ & $27.1^{\mathrm{b}}$ & $26.6^{\mathrm{bc}}$ & $27.3^{\mathrm{bd}}$ & 0.75 & $5.42^{* *}$ \\
Feed conversion (feed/gain) & $4.5^{\mathrm{a}}$ & $5.8^{\mathrm{b}}$ & $5.9^{\mathrm{bc}}$ & $6.4^{\mathrm{bd}}$ & 0.22 & $3.17^{* * *}$ \\
Liver weight (g) & $11.1^{\mathrm{a}}$ & $10.8^{\mathrm{a}}$ & $11.0^{\mathrm{a}}$ & $10.5^{\mathrm{a}}$ & 0.46 & 0.35 \\
Liver weight/Body weight (\%) & $3.1^{\mathrm{a}}$ & $3.0^{\mathrm{a}}$ & $3.2^{\mathrm{a}}$ & $3.0^{\mathrm{a}}$ & 0.09 & 0.57 \\
\hline
\end{tabular}

${ }^{1)}$ Standard error of means.

${ }^{\text {abcd }}$ Means with bearing the same letters did not differ significantly $(p>0.05), *<0.05, * *<0.01, * * *<0.001$.

Table 3. Least square means and pair differences for lipid contents in blood serum as a function of basal feeding (C) and $20 \%$ of sausage supplementation containing $0 \%$ saponin (S0), $2 \%$ saponin (S2), or $4 \%$ saponin (S4)

\begin{tabular}{lcccccc}
\hline \hline \multicolumn{1}{c}{ Items $(\mathrm{mg} / \mathrm{dL})$} & $\mathrm{C}(\mathrm{n}=8)$ & $\mathrm{S} 0(\mathrm{n}=8)$ & $\mathrm{S} 2(\mathrm{n}=8)$ & $\mathrm{S} 4(\mathrm{n}=8)$ & SEM $^{1)}$ & $\mathrm{F}$ value \\
\hline Total cholesterol & $147.9^{\mathrm{a}}$ & $183.7^{\mathrm{b}}$ & $100.5^{\mathrm{c}}$ & $100.0^{\mathrm{cd}}$ & 9.12 & $19.79^{* * *}$ \\
Triglyceride & $135.1^{\mathrm{a}}$ & $145.8^{\mathrm{a}}$ & $75.2^{\mathrm{bd}}$ & $78.3^{\mathrm{cd}}$ & 10.98 & $11.40^{* * *}$ \\
HDL-cholesterol & $86.0^{\mathrm{a}}$ & $101.0^{\mathrm{ab}}$ & $107.0^{\mathrm{bc}}$ & $102.0^{\mathrm{ac}}$ & 5.77 & 2.48 \\
LDL-cholesterol & $34.9^{\mathrm{a}}$ & $19.9^{\mathrm{ab}}$ & $13.9^{\mathrm{bc}}$ & $18.8^{\mathrm{ac}}$ & 5.77 & 2.48 \\
\hline
\end{tabular}

${ }^{1)}$ Standard error of means.

${ }^{\text {abcd }}$ Means with bearing the same letters did not differ significantly $(p>0.05), * * *<0.001$. 
centrations were reduced in rabbits fed for 4 wk on the saponin extracted from red ginseng (Inoue et al., 1999) and it was reported that, when high cholesterol feed was supplied to the rats, cultured ginseng powder reduced blood cholesterol and triglyceride concentrations (Lee et al., 2003). In a previous study conducted by Yoon and Joo (1993), $100 \mathrm{mg}$ of cholesterol and $1 \mathrm{mg}$ of ginseng saponin were orally administered together to rats every day for $15 \mathrm{~d}$; the total cholesterol levels in those rats were reduced by approximately $25 \%$ compared to the controls. Chung et al. (1992) fed mice on arteriosclerosis-inducing diets for $4 \mathrm{wk}$ and then administered ginseng saponin to the mice for $2 \mathrm{wk}$ in combination with the same diet, and noted that the total cholesterol and triglyceride concentrations in those rats decreased by around 42 and $38 \%$, respectively, compared to the controls.

Serum HDL-cholesterol is an index of anti-arteriosclerosis and is synthesized principally in the liver. It is widely regarded as the "good cholesterol" since, unlike other lipoproteins; it separates the LDL-cholesterol from the blood vessel walls and moves to the liver, thereby reducing the risk of cardiovascular system diseases (Gordon et al., 1977). It is also known that the blood concentration of LDL-cholesterol is determined by the conversion of VLDL (very low density lipoprotein) to LDL-cholesterol by the action of lipoprotein lipase, as well as the number of LDL receptors in the liver (Havel, 1961). In particular, it has been reported that, although HDL-cholesterol concentrations are not affected profoundly by dietary factors, they can be substantially increased by exposure to certain physiologically active plant materials (Cha et al., 2000). In this experiment, however, no statistically significant differences in HDL-cholesterol and LDL-cholesterol caused by the addition of saponin were recognized in the experimental group provided with feed supplemented with sausages containing saponin. This result was similar to the findings of a study conducted by Chung et al. (1992) in which ginseng saponin was administered to mice together with an arteriosclerosis-inducing diet, but no effects on HDL-cholesterol concentrations were detected. However,
Cha et al. (2003) reported different results indicating that, when fat was added at a level of $20 \%$ and 200 or $400 \mathrm{mg}$ of red ginseng powder were added to the diets of rats, HDL-cholesterol concentrations were increased significantly as compared to the control group.

\section{Liver lipid concentration}

The liver is the organ in which most lipid metabolism occurs, and also plays an important role in the removal of triglycerides and cholesterols. If the triglycerides processed in the liver are not removed properly, they can accumulate, leading to a fatty liver (Schaefer, 1995). Cholesterol is converted into bile acid in the liver; although this process is a major mechanism for the removal of cholesterol from the body, a vast array of regulatory proteins and enzymes are involved and can affect this metabolic process. Therefore, in this experiment, we assessed the effects of sausages containing added ginseng saponin on the total lipid, cholesterol and triglyceride concentrations in the liver. The results are shown in Table 4. In terms of total lipid contents, there was no difference between the sausage addition groups, whereas the $\mathrm{S} 4$ group exhibited a significant $(p<0.05)$ reduction of around $12 \%$ compared to the control group. The liver total cholesterol concentration were not significantly different between the control group and the S0 group, whereas the concentration decreased with increasing amounts of added saponin; in particular, the S4 group evidenced a significant $(p<0.05)$ reduction (around 14\%) as compared to the S0 group. Triglyceride concentrations in the liver exhibited a tendency identical to that of the resultant cholesterol concentrations and although none of those results achieved statistical significance, in the case of the sausage addition groups, groups S2 and S4 exhibited 7 and 31\% reductions, respectively, as compared to the S0 group. With regard to these decreasing cholesterol and triglyceride concentrations, Park et al. (2002) reported a similar case in which ginsenoside $\mathrm{Rb}_{1}$ was injected into the abdominal cavity for 3 days and the cholesterol and triglyceride concentrations in the liver consequently decreased. Kang et al. (1986)

Table 4. Least square means and pair differences for lipid contents in liver tissue as a function of basal feeding (C) and $20 \%$ of sausage supplementation containing $0 \%$ saponin (S0), $2 \%$ saponin (S2), or $4 \%$ saponin (S4)

\begin{tabular}{|c|c|c|c|c|c|c|}
\hline Items & $C(n=8)$ & $\mathrm{S} 0(\mathrm{n}=8)$ & $\mathrm{S} 2(\mathrm{n}=8)$ & $\mathrm{S} 4(\mathrm{n}=8)$ & $\mathrm{SEM}^{1)}$ & $\mathrm{F}$ value \\
\hline Total lipid (\%) & $5.0^{\mathrm{a}}$ & $4.8^{\mathrm{ab}}$ & $5.2^{\mathrm{a}}$ & $4.4^{\mathrm{b}}$ & 0.17 & $4.29 *$ \\
\hline Total cholesterol (mg/g) & $6.8^{\mathrm{ab}}$ & $7.3^{\mathrm{a}}$ & $7.2^{\mathrm{a}}$ & $6.3^{\mathrm{b}}$ & 0.26 & $3.40^{*}$ \\
\hline Triglyceride $(\mathrm{mg} / \mathrm{g})$ & $7.5^{\mathrm{a}}$ & $9.5^{\mathrm{ab}}$ & $8.8^{\mathrm{a}}$ & $6.6^{\mathrm{a}}$ & 0.87 & 2.22 \\
\hline
\end{tabular}

${ }^{1)}$ Standard error of means.

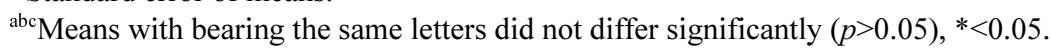


conducted a study in which rabbits were fed on high cholesterol diets for long periods of time to induce hypercholesterolemia in order to observe the effects of ginseng saponin on the distribution of serum lipoprotein concentrations as well as LDL and cholesterol metabolism; they reported that ginseng saponin promoted the formation of bile acid in the liver and decreased cholesterol concentration in the liver. Additionally, Joo et al. (1987) reported that, when several types of ginseng saponin fractions were administered to rats together with high cholesterol diets, the cholesterol concentrations in the liver were markedly reduced and the biosynthesis of LDL receptors was promoted significantly. However, the results of a study conducted by Do et al. (2001) demonstrated that when diets supplemented with cholesterol and ginseng powder were administered to rats, cholesterol and triglyceride concentrations in the liver did not differ from those of the control group. In our study, by providing ginseng sausages containing saponin to rats, cholesterol and triglyceride levels in the serum and liver were markedly reduced, suggesting that the saponin exerted a direct effect on lipid concentrations. Therefore, in future studies the effects of saponin on the activities of major regulatory proteins involved in lipid metabolism, LDL receptors, HMG-CoA reductase, and $7 \alpha$-hydroxylase, and the principal enzymes involved in lipogenesis and lipolysis in the liver should be assessed in greater detail.

\section{Fatty acid composition}

The fatty acid compositions of the liver tissues in the rats fed on sausages containing ginseng saponin are shown in Table 5. Palmitic acid (16:0) levels were significantly $(p<0.05)$ reduced in the S0 and S4 groups as compared to the control group, while no differences were noted between the sausage-added diet groups. Oleic acid (18:1) evidenced significantly $(p<0.01)$ increased values in the S2 group as compared to the control group, whereas no differences were observed between the sausage-added diet groups. The linoleic acid (18:2) $(p<0.01)$ and linolenic acid (18:3) $(p<0.001)$ contents in the liver tissues were significantly reduced in the sausage groups as compared to the control group; among the sausage-added diet groups, the contents were significantly higher in the S2 group than in the S0 group, respectively, while there were no differences between the S4 group and the S0 group. Eicosanoic acid (20:1) contents did not differ between the S2 group and S4 group, but were significantly $(p<0.01)$ increased in the S2 group compared to the control and S0 groups. Eicosatrienoic aicd (20:3) contents increased significantly $(p<0.05)$ in the sausage-added diet groups compared to the control group, but did not differ among between the sausage-added diet groups. Although the results were not statistically significant, unsaturated fatty acid contents evidenced a tendency toward increase in the $\mathrm{S} 2$ group as compared to the control and S0 groups. In this experiment, in the group fed on sausages containing

Table 5. Least square means and pair differences for fatty acid in liver tissue as a function of basal feeding (C) and $20 \%$ of sausage supplementation containing $0 \%$ saponin (S0), $2 \%$ saponin (S2), or $4 \%$ saponin (S4)

\begin{tabular}{|c|c|c|c|c|c|c|}
\hline Fatty acid & $\mathrm{C}(\mathrm{n}=8)$ & S0 $(n=8)$ & $\mathrm{S} 2(\mathrm{n}=8)$ & $\mathrm{S} 4(\mathrm{n}=8)$ & SEM $^{1)}$ & F value \\
\hline C14:0 & $0.3^{\mathrm{a}}$ & $0.3^{\mathrm{a}}$ & $0.3^{\mathrm{a}}$ & $0.3^{\mathrm{a}}$ & 0.03 & 0.49 \\
\hline C15:0 & $0.1^{\mathrm{a}}$ & $0.1^{\mathrm{a}}$ & $0.1^{\mathrm{a}}$ & $0.1^{\mathrm{a}}$ & 0.01 & 1.32 \\
\hline C16:0 & $20.5^{\mathrm{a}}$ & $19.3^{\mathrm{b}}$ & $19.8^{\mathrm{ab}}$ & $19.4^{\mathrm{b}}$ & 0.30 & $3.06^{*}$ \\
\hline C17:0 & $0.3^{\mathrm{a}}$ & $0.3^{\mathrm{a}}$ & $0.3^{\mathrm{a}}$ & $0.3^{\mathrm{a}}$ & 0.02 & 1.8 \\
\hline C18:0 & $13.4^{\mathrm{ab}}$ & $14.7^{\mathrm{b}}$ & $12.1^{\mathrm{a}}$ & $16.3^{\mathrm{ab}}$ & 1.51 & 1.45 \\
\hline C18:1 & $17.9^{\mathrm{a}}$ & $20.2^{\mathrm{ab}}$ & $23.4^{\mathrm{b}}$ & $20.3^{\mathrm{ab}}$ & 1.13 & $4.10^{* *}$ \\
\hline C18:2 & $19.8^{\mathrm{a}}$ & $15.7^{\mathrm{c}}$ & $17.5^{\mathrm{b}}$ & $14.4^{\mathrm{bc}}$ & 1.21 & $3.50 * *$ \\
\hline C18:3 & $0.8^{\mathrm{a}}$ & $0.5^{\mathrm{c}}$ & $0.6^{\mathrm{b}}$ & $0.6^{\mathrm{bc}}$ & 0.04 & $14.15^{* * *}$ \\
\hline C20:1 & $0.1^{\mathrm{a}}$ & $0.2^{\mathrm{ab}}$ & $0.3^{\mathrm{c}}$ & $0.2^{\mathrm{bc}}$ & 0.02 & $5.16^{* *}$ \\
\hline $\mathrm{C} 20: 2$ & $0.3^{\mathrm{a}}$ & $0.3^{\mathrm{a}}$ & $0.4^{\mathrm{a}}$ & $0.3^{\mathrm{a}}$ & 0.04 & 0.43 \\
\hline C20:3 & $0.2^{\mathrm{a}}$ & $0.3^{\mathrm{b}}$ & $0.3^{\mathrm{b}}$ & $0.3^{\mathrm{b}}$ & 0.02 & $3.70 *$ \\
\hline C20:4 & $21.5^{\mathrm{a}}$ & $23.0^{\mathrm{a}}$ & $20.6^{\mathrm{a}}$ & $22.8^{\mathrm{a}}$ & 0.90 & 1.67 \\
\hline C20:5 & $0.7^{\mathrm{a}}$ & $0.8^{\mathrm{a}}$ & $0.8^{\mathrm{a}}$ & $0.8^{\mathrm{a}}$ & 0.04 & 0.68 \\
\hline $\mathrm{C} 22: 6$ & $3.9^{\mathrm{ab}}$ & $4.2^{\mathrm{a}}$ & $3.6^{\mathrm{b}}$ & $3.8^{\mathrm{ab}}$ & 0.16 & 1.99 \\
\hline $\mathrm{SFA}^{2)}$ & $34.7^{\mathrm{a}}$ & $34.9^{\mathrm{a}}$ & $32.5^{\mathrm{b}}$ & $36.5^{\mathrm{ab}}$ & 1.36 & 1.5 \\
\hline USFA $^{3)}$ & $65.3^{\mathrm{a}}$ & $65.1^{\mathrm{a}}$ & $67.5^{\mathrm{b}}$ & $63.5^{\mathrm{ab}}$ & 1.36 & 1.45 \\
\hline
\end{tabular}

${ }^{1)}$ Standard error of means.

${ }^{\mathrm{abc}}$ Means with bearing the same letters did not differ significantly $(p>0.05), *<0.05, * *<0.01, * * *<0.001$.

${ }^{2)}$ SFA (saturated fatty acid).

${ }^{3)}$ USFA (unsaturated fatty acid). 
$2 \%$ ginseng saponin (S2 group), the most profound change in fatty acid composition involved changes in unsaturated and essential fatty acid concentrations. It is known that, in general, saturated fatty acids increase total blood cholesterol and low density lipoprotein cholesterol concentrations, whereas highly unsaturated fatty acids reduce total cholesterol concentrations and increase high density lipoprotein cholesterol concentrations (Shepherd et al., 1980). In particular, among the highly unsaturated fatty acids, the n-3 and n- 6 family fatty acids are known to reduce harmful cholesterol contents in the blood (Simopoulos, 1988) and reduce triglyceride concentrations in the livers of mice, in addition to their importance as essential fatty acids (Moir et al., 1995). Thus, reductions in the total cholesterol and triglyceride concentrations in serum and liver tissues are considered to have resulted from the ginseng saponin-induced increases in unsaturated and essential fatty acid content.

Although the current study adopted a rat model, the data implied that, supplementation of emulsified sausages with ginseng saponin could decrease cholesterol and triglyceride levels in serum and liver. It was postulated based on concomitant cascade of lipid information that the reduction in lipid level is likely linked to increased unsaturated and essential fatty acid compositions. It is not necessary to extend the current data to human model, but the data highlight a positive aspect of emulsified sausage on fat metabolism. Therefore, the meat industry could use ginseng saponin as an additive to produce the functional sausage or meat products.

\section{References}

1. Brekhman, I. I. and Dardymov, I. V. (1969) New substances of plant origin which increase non-specific resistance. Ann. Rev. Pharmacol. 9, 419-430.

2. Cha, J. Y., Jun B. S., and Cho, Y. S. (2003) Effect of Korean red ginseng powder on the lipid concentrations and tissue lipid peroxidation in the rats fed high fat diet. J. Korean Soc. Food Sci. Nutr. 32, 124-130.

3. Cha, J. Y., Kim, H. J., Jun, B. S., and Cho, Y. S. (2000) Effect of water extract of leaves from Morus alba and Cudrania tricuspidata on the lipid concentration of serum and liver in rats. Agric. Chem. Biotehnol. 43, 303-308.

4. Cho, S. Y., Park, J. Y., and Jang, J. Y. (2000) Effect of dandelion leaf extracts on lipid metabolism in rats fed high cholesterol diet. J. Korean Soc. Food Sci. Nutr. 29, 675-682.

5. Choi, S. H. and Chin, K. B. (2002) Development of low-fat comminuted sausage manufactured with various fat replacers similar textural characteristics to those with regularfat counterpart. Korean J. Food. Sci. Thechnol. 34, 577-582.
6. Chung, Y. H., Hwng, Y. S., Joo, C. N., and Paik, Y. K. (1992) Effects of colestipol and ginseng saponin on the cholesterol metabolism in mice. J. Kor. Lipid. 2, 16-23.

7. Do, K. M., Park, Y. B., Bok, S. H., Lee, M. K., Jeong, T. S., and Choi, M. S. (2001) Alteration of lipid metabolism by ginseng supplements with different levels of vitamin $\mathrm{E}$ in high cholesterol-fed rats. J. Food Sci. Nutr. 6, 66-72.

8. Folch, J., Lees, M., and Sloan-Stanley, G. H. (1957) A simple method for the isolstion and purification of total lipids from animal tissues. J. Bio. Chem. 226, 497-507.

9. Friedewald, W. T., Levy, R. I., and Fredrickson, D.S. (1972) Estimation of concentration of low-density lipoprotein cholesterol in plasma without use of the ultracentrifuge. Clin. Chem. 18, 449-502.

10. Gordon, T., Casfelli, W. P., Hjortland, M. C., Kennel, W. B., and Dawher, T. R. (1997) High density lipoprotein as a protective factor against coronary heart diseases, the Framingham study. Am. J. Med. 62, 707-714.

11. Hamsten, A. (1988). Aplipoproteins dyslipoprotenaemia and premature coronary heart disease. Acta. Med. Scand. 223, 389-394.

12. Havel, R. J. (1961) Conversion of plasma free fatty acids into triglycerides of plasma lipoprotein fractions in man. Metabolism 10, 1031-1034.

13. Inkeles, S. and Eisenberg D. (1981) Hyperlipidemia and coronary antherosclerosis. Medicine 60, 110-123.

14. Inoue, M., Wu, C. Z., Dou, D. G., Chen, Y. J., and Ogihara, Y. (1999) Lipoprotein lipase activation by red ginseng saponins in hyperlipidemia model animals. Phytomedicine 6 , 257-265.

15. Joo, C. N., Choi, J. Y., and Lee, Y. W. (1987) Biosythesis of low density lipoprotein receptor: Stimulation of liver cholesterol metabolism by ginsenosides. Korean Biochem. J. 20, 368-372.

16. Joung, I. S. and Cho, Y. D. (1985) Effect of ginseng saponin fraction on absorption of cholesterol and serum lipid components. Korean J. Ginseng Sci. 9, 222-239.

17. Kang, B. H. and Joo, C. N. (1986) Biochemical studies on ginseng saponin (XXVI). The effect of ginseng saonin fraction on low density lipoprotein (LDL) uptake by rat and rabbit livers. Korean Biochem. J. 19, 168-172.

18. Kim, B. K., Shin, G. K., Jeon, B. S. Bae, D. W., and Cha, J. Y. (2001) Cholesterol-lowering effect of mushroom powder in hyperlipidemic rats. J. Korean. Soc. Food Sci. Nutr. 30, 510-515.

19. Kurata, M., Narikawa, T., Waki, M., Koh, H., Maruyama, T., and Nambu, S. (1990) Relationships between serum cholesterol and obesity: A field study on nutritional background of hypercholesterolemia. Diabetes Res. Cli. Pract. 10, 239-245.

20. Lee, H. K. (1996) Nutritional problems of Koreans: pattern of disease incidence and nutrition in Korea. Korean J. Nutr. 29, 381-383.

21. Lee, I. S., Lee, S., and Lee, I. Z. (2003) Effects of tissue cultured ginseng on blood glucose and lipids in streptozotocininduced diabetic rats. Korean J. Food Sci. Thechol. 35, 280258. 
22. Lee, J. W., Lee, S. K., and Do, J. H. (2002) Comparison of the content of saponin and mineral component in Korean red ginseng and other ginseng. Ginseng Res. 26, 196-201.

23. Lin, S. G., Zheng, X. L., Chen, Q. Y., and Sun, J. J. (1993) Effect of Panax notoginseng saponins on increased proliferation of cultured aortic smooth muscle cells stimulated by hypercholesterolemic serum. Zhongguo Yao Li Xue Bao 14, 314-6.

24. Moir, A. M., Park, B. S., and Zammit, V. A. (1995) Quantification in vivo of the effects of different types of dietary fat on the loci of control involved in hepatic triacylglycerol secretion. Biochem. J. 308, 537-547.

25. Moon, K. S. (1985) Components and utilization of medical plants. Ilwonseogak Co., Seoul, Korea pp. 500 (in Korean).

26. Park, K. H., Shin, H. J., Song, Y. B., Hyun, H. C., Cho, H. Y., Ham, H. S., Yoo, Y. B., Ko, Y. C., Jun, W. T., and Park, H. J. (2002) Possible role of ginsenoside Rb1 on regulation of rat liver triglycerides. Biol. Pharm. Bull. 25, 457-60.

27. Park, P. W. and Goins, R. E. (1999) In situ preparation of fatty acid methyl esters for analysis of fatty acid composition in foods. J. Food Sci. 59, 1262-1266.

28. Pearson, A. M., Asghjar, A., Gray, J. I., and Booren, A. M. (1987) Impact of fat reduction on palatability and consumer acceptance of processed meat. Preced $46^{\text {th }}$ Ann. Recip. Meat Conf. 40, 105-114.

29. SAS (1997) SAS/STAT Software for PC, SAS Institute INC, Cary, NC, USA.

30. Schaefer, E. J. (1995) Lipoproteins, nutrition, aging and atherosclerosis. Am. J. Clin. Nutr. 61, 726.

31. Shephered, J., Packard, C. J., Grundy, S. M., Yeshumin, D., Gotto, A. M., and Taunton, O. D. (1980) Effect of saturated and unsaturated fat diets in the chemical composition and metabolism of low density lipoprotein in man. J. Lipid Res. 21, 91-9.

32. Simopoulos, A. P. (1988) $\omega-3$ fatty acids in growth and development part II. The role of $\omega-3$ fatty acids in health and disease: Dietary implication. Nutrition today 23, 10-19.

33. Stavro, P. M., Woo, M., Heim, T. F., Leiter, L. A., and Vuksan, V. (2005) North American ginseng exerts a neutral effect on blood pressure in individuals with hypertension. Hypertension 46, 406-411.

34. Wen, Y., Pei, Y., Chen, Y., Wang, Z., Ma, Z., Wang, M., and Li, W. (1996) Effects of ginsenosides from stems and leaves on hyperlipemia induced by prednisone acetate in rabbits. Zhongguo Zhong Yao Za Zhi 21, 430-431, 448.

35. Yamamoto, M., Uemura, Nakama, S., Uemiya, M., and Kumagai, A. (1983) Serum HDL-cholesterol increasing and fatty liver improving actions of Panax ginseng in high cholesterol diet-fed rats with clinical effect on hyperlipidemia in man. Am. J. Chin. Med. 11, 96-101.

36. Yang, Y., Wu, T., He, K., and Fu, Z. G. (1999) Effect of aerobic exercise and ginsenosides on lipid metabolism in dietinduced hyperlipidemia mice. Zhongguo Yao Li Xue Bao 20, 563-565.

37. Yoon, S. H. and Joo, C. N. (1993) Study on the preventive effect of ginsenosides against hypercholesterolemia and its mechanism. Korean J. Ginseng Sci. 17, 1-12.

38. Zhang, Y. G., Zhang, H. G., Zhang, G. Y., Fan, J. S., Li, X. H., Liu, Y. H., Li, S. H., Lian, X. M., and Tang, Z. (2008) Panax notoginseng saponins attenuate atherosclerosis in rats by regulating the blood lipid profile and an anti-inflammatory action. Clin. Exp. Pharmacol. Physiol. 35, 1238-1244.

(Received 2010.3.31/Revised 2010.6.17/Accepted 2010.6.21) 